\title{
Evaluation of the natural killer cytotoxicity and the levels of cytokines in rats with type I diabetes mellitus
}

\author{
Isil Fidan/ ${ }^{+}$, Sevgi Yüksel, Ayse Kalkanci, Turgut Imir, Semra Kustimur
}

Department of Medical Microbiology, Faculty of Medicine, Gazi University, Besevler, Ankara 06500, Turkey

Type I diabetes mellitus (insulin-dependent DM = IDDM) is a chronic disease characterized by specific destruction of pancreatic $\beta$ cells, resulting in an absolute lack of insulin. Immune mechanisms, genetic susceptibility, and environmental factors are all implicated in the pathogenesis of Type 1 diabetes. This study was aimed at determining the efficiency of cytokines, natural killer (NK) cells in the pathophysiology of IDDM. Therefore, we evaluated the plasma levels of cytokines by specific enzyme-linked immunosorbent assay (ELISA) and the cytotoxicity activity of NK cells by anti-candididal index in rats with type I diabetes. We found that the cytotoxicity activity of NK cells in IDDM groups significantly decreased compared to the control groups. The levels of interferon- $\gamma(I F N-\gamma)$ in IDDM groups were slightly higher than in healthy controls. These results indicate that the changes of $T_{H} 1$ type cytokines such as IFN-rand NK cell activity can play a role in the etiology of IDDM. The data may provide new strategies for the treatment of IDDM.

Key words: Type 1 diabetes mellitus - cytokines - natural killer cells

Type I diabetes mellitus (insulin-dependent $\mathrm{DM}=$ IDDM) is a chronic disease characterized by specific destruction of pancreatic $\beta$-cells, resulting in an absolute lack of insulin (Boitard 2002). Immune mechanisms, genetic susceptibility, and environmental factors are all implicated in the pathogenesis of Type 1 diabetes. There are many recent evidences that the immune system may be involved in the pathogenesis of IDDM in humans as well as in animal models (MacKay et al. 1986). There is an autoimmune destruction of the insulin-producing $\beta$-cells in the pancreatic islets of Langerhans. Recent studies in humans and animals suggest that autoimmune diabetes is associated with an imbalance between $\mathrm{T}_{\mathrm{H}}$ 1-type cytokines and $\mathrm{T}_{\mathrm{H}}$ 2-type cytokines in immune system (Lo et al. 2004). Cytokines are small proteins which play a central role in the regulation of host defenses. $\mathrm{T}_{\mathrm{H}} 1$ cytokines (interferon$\gamma$, IFN- $\gamma$, interleukin- 2 , IL- 2 , tumor necrosis factor- $\beta$, TNF$\beta$ ) primarily activate cellular immune reponses whereas $\mathrm{T}_{\mathrm{H}} 2$ tip cytokines (IL-4, IL-6, IL-10) primarily stimulate humoral immune responses (Hayashi et al. 1998). It is suggested that the more production of $\mathrm{T}_{\mathrm{H}} 1$ type cytokines by islet-infiltrating leukocytes may induce $\beta$-cell destruction whereas the more production of $\mathrm{T}_{\mathrm{H}} 2$ type cytokines in islets may protect against $\beta$-cell destruction. Thus, $\mathrm{T}_{\mathrm{H}} 2$ type cytokines may have a protective role against the development of diabetes (Rabinovitch 1998).

Natural killer (NK) cells are a subset of mononuclear cells. They are nonphagocytic large granular lymphocytes which are cytotoxic for certain tumor cell lines and virally infected cells. NK cells play several important roles in the host defense against certain microorganisms (Baxter \&

${ }^{+}$Corresponding author. E-mail: isilfidan@yahoo.com, fidani@gazi.edu.tr

Received 20 July 2005

Accepted 16 November 2005
Smyth 2002). They secrete multiple immunomodulatory cytokines such as IFN- $\gamma$, TNF- $\alpha$, IL-10. (Abbas \& Zitchman 2003). Because of this property, NK cells have been suggested to play an immunoregulatory role in organspecific autoimmune disorders, such as type 1 diabetes (Johansson et al. 2004). It is considered that autoimmune diseases result from chronic viral infections and NK cells can inhibit disease by clearing virus (Baxter \& Smyth 2002). NK cells may play both pathological and protective roles in type 1 diabetes (Johansson et al 2004). Defects in NK cell numbers and their function have been identified in animal models of autoimmunity. In order to determine certain roles of NK cells and cytokines profiles in type 1 diabetes may provide new strategies for the treatment of diabetes.

The present study was aimed at determining the efficiency of cytokines such as TNF- $\alpha$, IL-1 $1 \beta$, IL- 2 , IFN- $\gamma$, and NK cells in the pathophysiology of IDDM. Therefore, we evaluated the plasma levels of cytokines and the cytotoxicity activity of NK cells in rats with type I diabetes.

\section{MATERIALS AND METHODS}

Animals - Eight female Wistar albino rats weigting 200$250 \mathrm{~g}$ were used in this study. All rats were 6-8 weeks old.

Streptozotocin-induced diabetic rats - The animal experiments were conducted according to the Guide for the Care and Use of Laboratory Animals of the Gazi University School of Medicine. Local Ethical Committee permissions were obtained. The experimental group $(n=8)$ was made diabetic by a single intraperitoneal injection of freshly dissolved streptozotosin (STZ, Sigma) $(45 \mathrm{mg} / \mathrm{kg}$ body weight in citrate buffer $0.01 \mathrm{M}, \mathrm{pH} 4.5)$ into overnight fasted rats. The control group $(n=8)$ was injected with buffer only. Forthy-eight hours after injection of STZ, the plasma levels of glucose were assessed. The plasma glucose levels were determined using a glucometer. Rats were defined as diabetic if their plasma glucose concentration was above $400 \mathrm{mg} / \mathrm{ml}$ and these rats were used in the experiment (Zhang \& Tan 2000). 
Isolation of lymphocytes for NK cytotoxicity assay (effector cell preparation) - Heparinized blood was collected from tail vein. Peripheral blood mononuclear cells (PBMCs) were isolated from blood by sedimentation on a Ficoll-hypaque gradient (Sigma). PBMCs were washed in phosphate buffered saline (PBS) three times and resuspended in RPMI 1640 medium containing $2 \mathrm{mmol} / \mathrm{l}$ glutamine, $200 \mathrm{U} / \mathrm{ml}$ penicillin, $100 \mathrm{mg} / \mathrm{ml}$ streptomycin, and supplemented with $10 \%$ foetal calf serum. The suspension of PBMC was poured into petri dishes sensitized autologous serum and was incubated $1 \mathrm{~h}$ at $37^{\circ} \mathrm{C}$. After incubation, non-adherent cells were gently harvested and same procedure was applied second time. The non-adherent cells washed in RPMI-1640 and used as the effector cells (Gülay \& Imir 1996). The relative percentage of monocytes was less than $5 \%$ as determined by morphological examination following Giemsa staining. Effector cell viability was $95 \%$ by the trypan blue exclusion test.

Target cell preparation for NK cytotoxicity assay Candida species (Candida albicans) used in this study were isolated from clinical specimens in our laboratory. Candida was grown on a blood agar base for 18 h. Yeast cells were resuspended in RPMI 1640 medium and adjusted to the concentration of $4 \times 10^{3}$ viable organisms $/ \mathrm{ml}$.

NK cytotoxicity assays (colony forming inhibition assay $=C F I)$ - NK cytotoxic activity was assessed by CFI assay. Yeast cells used as target cells were incubated with effector cells in 96-well U-bottomed microtitre plates at different target:effector (T:E) ratios (1:3 and 1:30) for $2 \mathrm{~h}$ at $37^{\circ} \mathrm{C}$ in a $\mathrm{CO}_{2}$ incubator. Control wells contained target cells in RPMI 1640 medium. After incubation, aliquots of $25 \mu 1$ from each well were plated on petri dishes containing Saburoud dextrose agar. Cultures were then incubated for $48 \mathrm{~h}$ at $37^{\circ} \mathrm{C}$ and colonies were counted. The percentage reduction in colony forming unit was determined as the anti-candidial index (ACI) according to the following formula:

$\mathrm{ACI}=(1-$ experimental colony forming unit/control colony forming unit $) \times 100$

Each experiment was performed in quadruplicate.

Cytokine assays - For cytokines assay, blood was collected from tail vein. After centrifugation, the plasma was collected and stored at $-80^{\circ} \mathrm{C}$ until analyzed. Levels of cytokines such as TNF- $\alpha$, IL-1, IL-2, IL-6, IL-10, IFN- $\gamma$ in plasma samples were determined by specific enzyme-linked immunosorbent assay (ELISA) techniques according to the manifacturer's instructions (Biosource, California, US). The concentration of cytokines was determined spectrophotometrically. The absorbance was read at $450 \mathrm{~nm}$. We constructed a standard curve using cytokines standards. The cytokine concentrations for unknown samples were calculated according to standard curve.

Statistical methods - The NK cytotoxicity and the cytokine concentrations from the rats with diabetes were compared with those from healthy controls using the Mann-Whitney U test; $\mathrm{p}<0.05$ was considered to be significant.

\section{RESULTS}

The percentage of inhibition of colony formation (ACI) found was 7, 12,14, 9, 11, 14; 8 and 15\% for T:E ratios of $1: 3$ in 8 rats with diabetes and $23,32,24,25,32,29 ; 34,26 \%$ for T:E ratios of 1:30 in 8 rats with diabetes. The difference between T:E ratios of 1:3 and 1:30 in ACI was statistically significant.

The percentage of ACI found was 18, 29, 25, 27, 24, $37 ; 16$ and $23 \%$ for T:E ratios of 1:3 in control groups and $32,50,48,57,53,54 ; 56,63 \%$ for T:E ratios of $1: 30$ in control groups.

The comparative results of ACI for T:E ratios of 1:3 and 1:30 in diabetic and control groups were shown in Figs 1 and 2, respectively. There was a significant difference between diabetic groups and control groups $(\mathrm{p}<$ $0.05)$.

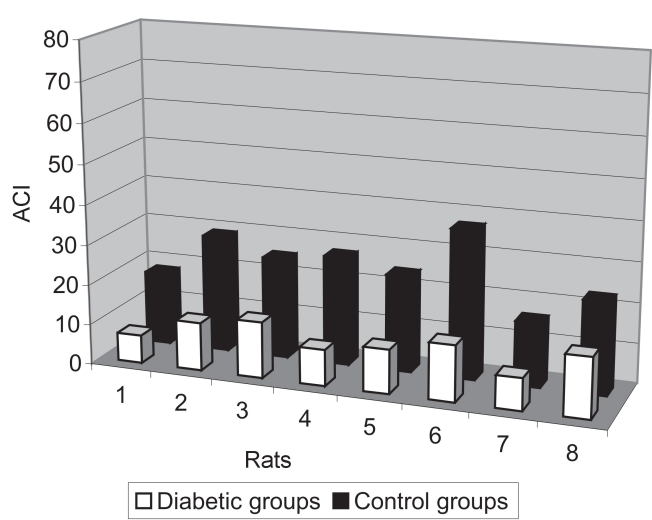

Fig. 1: the comparative results of anti-candicial index (ACI) for target:efector ratios of 1:3 in diabetic and control groups (\%).

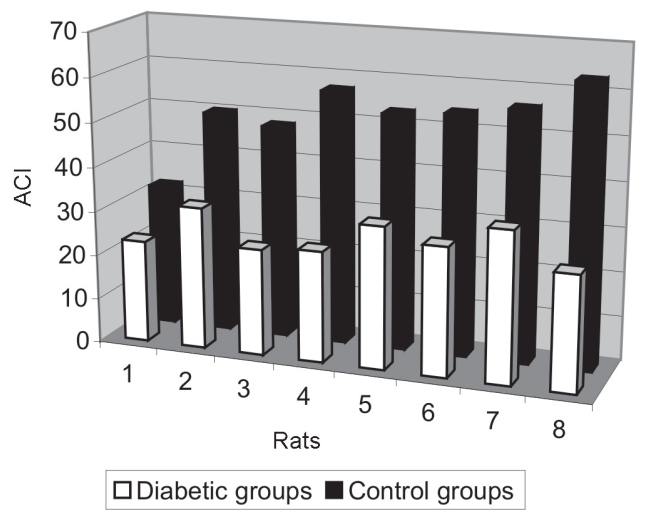

Fig. 2: the comparative results of anti-candicial index (ACI) for target:efector ratios of 1:30 in diabetic and control groups (\%).

In this study we could not demostrate that diabetic groups differ in serum concentrations of TNF- $\alpha$, IL-1, IL2, IL-6, IL-10 from controls (Fig. 3) ( $p>0.05$ ). However, IFN- $\gamma$ plasma levels in diabetic rats were significantly higher than in healthy controls (Fig. 4) $(\mathrm{p}<0.05)$ (Table I).

\section{DISCUSSION}

Type $1 \mathrm{DM}$ is a immune-mediated disease characterized by specific destruction of insulin-producing $\beta$ cells 

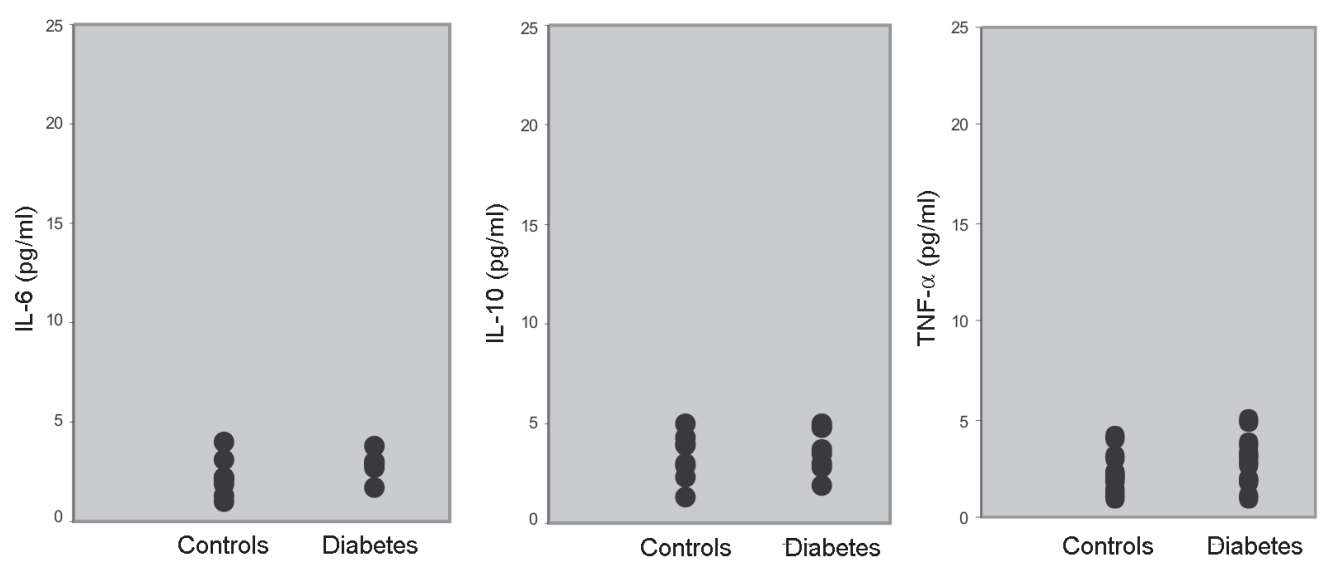

Fig. 3: the levels of interleukin-6, interleukin-10 and tumour necrosis factor- $\alpha$.

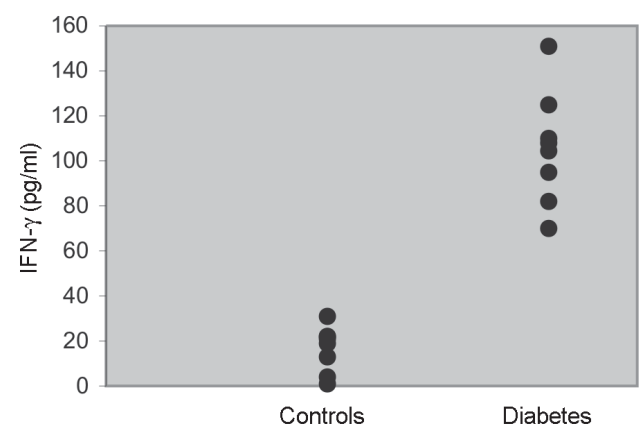

Fig. 4: the levels of interferon- $\gamma($ IFN- $\gamma)(n=8)$.

TABLE

Mean, standart deviation (SD), standard error (SE) values for interferon- $\gamma$

\begin{tabular}{lcc}
\hline & Control groups & Diabetic groups \\
\hline Mean & 16.6 & 109.17 \\
SD & 10.04 & 27.59 \\
SE & 3.55 & 9.75 \\
\hline
\end{tabular}

of the pancreatic islets, resulting in the loss of glucose homeostasis (Poirot et al. 2004). The most important aim of the research on DM is to have an understanding of the genetics and immunopathological basis of the disease because it may provide new therapy strategies. Recent evidence from animal models of autoimmune diabetes indicates that there is an autoimmune attack directed against $\beta$-cells in IDDM. This effect may be due to impaired immunoregulatory balance (Rapoport et al. 1998). Thus, we investigated the roles of NK cells and cytokines in diabetic rats. Therefore, the plasma levels of cytokines and the cytotoxicity activity of NK cells in rats with type I diabetes were studied and compared with those of controls.

In order to determine NK cytotoxic activity, we used CFI assay. In this procedure, target cells $(\mathrm{T}=$ Candida $)$ were incubated with effector cells $(E=$ rat lymphocytes) at different $\mathrm{T}$ :E ratios (1:3 and 1:30) and $\mathrm{ACI}$ was determined. There was an increase in the ACI; both ratios in diabetic groups were compared with controls and the result was significant (Figs 1,2) $(\mathrm{p}<0.05)$. Accordingly, we found significant decrease in the cytotoxicity activity of NK cells in IDDM groups compared with control groups.

Negishi et al. (1986) observed that NK cell activity against target cells decreased in new onset Type 1 diabetes patients whereas Type 2 diabetic patients displayed similar range of NK activity compared to controls. They also thought that the decreased NK cell activity in diabetes could be due to several factors; that is, either IFN production is deficient in Type 1 diabetes or NK cell sensitivity to IFN is reduced. Hussain et al. (1987) demostrated that Type 1 diabetic patients tended to have reduced numbers of natural killer cells. Similarly, Lorini et al. (1994) observed that NK cytotoxic activity decreased in IDDM patients.

Ellerman et al. (1993) demonstrated that chronic treatment of the BB/Wor diabetes-prone rats with monoclonal antibodies that removed circulating NK cells did not protect against diabetes or delay its onset. Thus, they informed that NK cells were not necessary for the development of spontaneous diabetes in BB/Wor rats. Poultan et al. (2001) informed that NOD (non-obese diabetic mice), used as a spontaneous model of type $1 \mathrm{DM}$, had a relative deficiency in peripheral NK cells and a defect in NK cell export. They also observed deficiencies in NK cell activity. Johansson et al. (2004) found that the numbers of NK cells were similar in NOD mice and controls. However, they indicated a NK cell defect in cytotoxic potential in NOD. In addition, they suggested that there was an inverse correlation between NK activity and diabetes incidence.

MacKay et al. (1986) demonstrated that NK cell activity increased in BB/W rats acutely diabetic. But they had no direct evidence that DM is an NK-cell mediated disease in rats. They also informed that NK cells per se might be insuffient to cause diabetes.

In spite of these studies, the role of NK cells in type 1 
diabetes is still unclear. Conficting results have been reported on the role of NK cells in diabetes. The results obtained from our study suggest that NK cells can play a role in the pathogenesis of type $1 \mathrm{DM}$. We think that the NK cells cytotoxic activities impair type 1 diabetes. If the certain role of NK cells in diabetes is determined, new therapy strategies can be improved. In the study of Coutant et al. (1998) low-dose linomide which stimulates NK cells, reduced the insulin needs and improved beta cell function in patients with type 1 diabetes.

Autoimmune type $1 \mathrm{DM}$ is thought to result from the T-cell mediated immune destruction of the $\beta$-cells. Studies have shown that $\mathrm{T}_{\mathrm{H}} 1$ cytokines profiles (IL-12, IFN- $\gamma$ ) drive the diabetogenic process, whereas $\mathrm{T}_{\mathrm{H}} 2$ immunological responses (IL-4, IL-10) prevent diabetes development (Cetkovic-Cvrlje \& Uckun 2005). In this study, we found no significant difference in the serum levels of TNF$\alpha$, IL-1, IL-2, IL-6, IL-10 in diabetic rats compared to healthy controls $(\mathrm{p}>0.05)$. On the otherhand, the levels of IFN- $\gamma$ were found to increase significantly in diabetic rats $(\mathrm{p}<0.05)$.

Schloot et al. (2002) found that serum levels of IFN- $\gamma$ were high in NOD mice compared to controls. But they did not determine an increase in the serum levels of IL-10. So, they informed that the ratio of IFN- $\gamma / \mathrm{IL}-10$, reflecting $\mathrm{T}_{\mathrm{H}} 1 / \mathrm{T}_{\mathrm{H}} 2$ balance in serum increased significantly in diabetic compared to non-diabetic NOD mice. Suk et al. (2001) found that IFN- $\gamma$ could induce apoptosis in pancreatic islet cells and play a role in diabetes. Hayashi et al. (1998) also suggested that IFN- $\gamma$ might play a role in islet inflammation leading to islet cell destruction. Monetini et al. (2004) informed that the release of IFN- $\gamma$ was markedly reduced in patients treated with oral insulin.

In our study, we determined that the levels of IFN- $\gamma$, $\mathrm{T}_{\mathrm{H}} 1$ type cytokines increased in diabetes whereas there was no increase in the levels of $\mathrm{T}_{\mathrm{H}} 2$ type cytokines such as IL-6, IL-10. Therefore, we think that $\mathrm{T}_{\mathrm{H}} 1$-type cytokines can cause destruction of the insulin-producing $\beta$-cells in pancreatic islets of Langerhans and play a role in the pathophysiology of diabetes.

In conclusion, the etiology of type 1 diabetes remains unclear. The results obtained from our study indicate that the changes of $T_{H} 1$ type cytokines such as IFN $\gamma$ and NK cell activity can play a role in the etiology of IDDM. The data may provide new strategies in type 1 diabetes, such as the administration of recombinant cytokines, cytokines antagonists, and the drugs affecting the numbers and functions of NK. Although these alternative treatments may not cure type 1 diabetes, they may be effective to correct some problems associated with type 1 diabetes.

\section{REFERENCES}

Abbas AK, Lichtman AH 2003. Innate immunity. In J Malley, $\mathrm{H}$ Krehling (eds), Cellular and Molecular Immunology, Saunders, Philadelphia, p. 275-297.

Baxter AG, Smyth MJ 2002. The role of NK Cells in disease. Autoimmunity 35: 1-14.

Boitard C 2002 The origin of type 1 diabetes: An disease? Diabetes Metab 28: 263-265.
Cetkovic-Cvrlje M, Uckun F 2005. Effect of targeted disruption of signal transducer and activator of transcription (Stat) 4 and Stat 6 genes on the diabets development induced by multipl low doses of streptozotocin. Clin Immunol 114: 299-306.

Coutant R, Landais P, Rosilio M 1998. Low dose linomide in type 1 juvenile diabetes of recent onset: a randomised placebo-controlled double blind trial. Diabetologia 41: 10401046.

Ellerman K, Wrobleski M, Rabinovitch A, Like A 1993. Natural killer cell depletion and diabetes mellitus in the BB/Wor rat (revisited). Diabetologia 36: 596-601.

Gülay Z, Imir T 1996. Anti-candidal activity of natural killer (NK) and lymphokine activated killer (LAK) lymphocytes in vitro. Immunobiology 195: 220-230.

Hayashi T, Morimoto M, Iwata H, Onodera T 1998. Interferon- $\gamma$ plays a role in pancreatic islet-cell destruction of reovirus type 2-induced diabetes-like syndrome in DBA/1 suckling mice. Int J Exp Pathol 79: 313-320.

Hussain MJ, Alviggi L, Millward BA, Leslie RDG, Pyke DA, Vergani D 1987. Evidence that the reduced number of natural killer cells in type 1 (insülin-dependent) diabetes may be genetically determined. Diabetologia 30: 907-911.

Johansson SE, Hall H, Björklund J, Hoglund P 2004. Broadly impaired NK cell function in non-obese diabetic mice is partially restored by NK cell activation in vivo and by IL12/IL-8 in vitro. Intern Immunol 16: 1-11.

Lo HC, Lin SC, Wang YM 2004. The relationship among serum cytokines, chemokine, nitric oxide, and leptin in children with type 1 diabetes mellitus. Clin Biochem 37: 666-672.

Lorini R, Moretta A, Valtorta A, d'Annunzio G 1994. Cytotoxic activity in children with insulin-dependent diabetes mellitus. Diabetes Res Clin Pract 23: 37-42.

Mackay P, Jacobson J, Rabinovitch A 1986. Spontaneous Diabetes mellitus in the Bio-Breeding/Worcester rat. J Clin Invest 77: 916-924.

Monetini L, Cavallo MG, Sarugeri E 2004. Cytokines profile and insulin antibody IgG subclasses in patients with recent onset Type 1 diabetes treated with oral insulin. Diabetalogia 47: 1795-1802.

Negishi K, Waldeck N, Chandy G 1986. Natural killer cell and islet killer cell activities in type 1 (insulin-dependent) diabetes. Diabetologia 29: 352-357.

Poirot L, Benoist C, Mathis D 2004. Natural killer cells disinguish innocuous and destructive forms of pancreatic islet autoimmunity. PNAS 101: 8102-8107.

Poulton LD, Smyth MJ, Hawke CG 2001. Cytometric and functional analyses of NK and NKT cell deficiencies in NOD mice. Intern Immunol 13: 887-896.

Rabinovitch A 1998. An update on cytokines in the pathogenesis of insulin-dependent diabetes mellitus. Diabetes Metab Rev 14: 129-151.

Rapoport MJ, Mor A, Vardi P, Ramot Y, Winkr R, Hindi A, Bistritzer T 1998. Decreased secretion of Th2 cytokines precedes up-regulated and delayed secretion of Th1 cytokines in activated peripheral blood mononuclear cells from patients with insulin-dependent diabetes mellitus. 
J Autoimmune 11: 635-642.

Schloot NC, Hanifi-Moghaddam P, Goebel C 2002. Serum IFN$\gamma$ and IL-10 levels are associated with disease progression in non-obese diabetic mice. Diabetes Metab Res Rev 18: 6470 .

Suk K, Kim S, Kim YH 2001. IFN- $\gamma /$ TNF- $\alpha$ synergism as the final effector in diabetes: a key role for STAT1/IFN regulatory factor-1 pathway in pancreatic b cell death. J Immunol 166: 4481-4489.

Zhang XF, Tan BKH 2000. Effects of an ethanolic extract of Gynura procumbens on serum glucose, cholesterol and triglyceride levels in normal and streptozotocin-induced diabetic rats. Singapore Med 41: 9-13. 